\title{
Mass Spectral Behavior of Some Homoleptic and Mixed Aryldichalcogenide Bis(Diphenylphosphino)Ferrocenenickel(II), Palladium(II), and Platinum(II), and Bis(Diisopropylphosphino)Ferrocenepalladium(II) Complexes
}

\author{
Emmanuel Y. Osei-Twum and Luis A. Litorja, Jr. \\ Research Institute, King Fahd University of Petroleum and Minerals, Dhahran, Saudi Arabia
}

James Darkwa and Letladi L. Maisela

Department of Chemistry, University of the Western Cape, Bellville, South Africa

\author{
Alain Lesimple and Orval Mamer \\ Mass Spectrometry Unit, McGill University, Montreal, Quebec, Canada
}

The mass spectral behavior of a number of organometallic complexes containing the Group 10 metals $\mathrm{Ni}, \mathrm{Pd}$, and $\mathrm{Pt}$, together with various thiolate ligands were studied. For $\mathrm{Pd}$, two main types of complexes, differing by the substituents on the phosphorus atom were studied. Types I and II were substituted with bis(diphenylphosphino)ferrocene and bis(diisopropylphosphino)ferrocene ligands, respectively. The Ni complexes, except for one, and the Pd Type I complexes had no molecular radical cations $\left(\mathrm{M}^{+}\right)$in their EI spectra. On the other hand, all the $\mathrm{Pt}$ complexes showed intense $\mathrm{M}^{+\cdot}$ ions in their EI spectra indicating that these complexes were more stable as radical cations than those of $\mathrm{Ni}$ and Pd. The FAB and MALDI spectra of all the complexes displayed intense quasi-molecular ions $\left(\mathrm{MH}^{+}\right)$and the fragmentations in both modes were similar. The MALDI spectra of several complexes displayed only $\mathrm{M}^{+\cdot}$ ions while one gave evidence of both $\mathrm{MH}^{+}$and $\mathrm{M}^{+\cdot}$ ions. Several Pd Type II complexes yielded intense $\mathrm{M}^{+\cdot}$ in their EI spectra. (J Am Soc Mass Spectrom 2005, 16, 94-99) (c) 2004 American Society for Mass Spectrometry

G roup 10 diphenylphosphinoferrocene (dppf) dichloro complexes, $\mathrm{M}(\mathrm{dppf}) \mathrm{Cl}_{2}$, particularly the Pd analogs, are known to have been used in various catalytic reactions including the crosscoupling of primary and secondary alkyl Grignard and alkylzinc reagents with organic halides [1]. In studies of the synthesis, structural determination, and stabilities of a series of organochalcogens of similar Group 10 metal complexes [2, 3], mass spectrometry played a very important role. Henderson et al. [4] and Traeger [5] have used electrospray ionization (ESI) extensively as a mild technique to elucidate the structures of thiosalicylic metal complexes and to study other transition-metal coordination complexes. It has been known since the inception of fast atom

Published online November 18, 2004

Address reprint requests to Dr. E. Y. Osei-Twum, Research Institute, King Fahd University of Petroleum and Minerals, KFUPM Box 1472, Dhahran 31261, Saudi Arabia. E-mail: eyosei@kfupm.edu.sa bombardment $(\mathrm{FAB})$ as an ionization technique, that it can be used for the analysis of transition-metal coordination complexes [6, 7]. We also found that FAB ionization is equally capable of producing $\mathrm{MH}^{+}$ ions of the Group 10 metal complexes [2, 3]. For example, arylchalcogenide ligand complexes like thiosalicylic acid and aryldichalcogenide ligands, such as 1,2-benzenedithiol and 3,4-toluenedithiol, readily show $\left(\mathrm{MH}^{+}\right)$ions in their $\mathrm{FAB}$ spectra, hence FAB mass spectrometry provides a very facile structural characterization tool for metal complexes of these ligands.

In a report on diethyldithiocarbamatonickel(II) thiolato complexes [8], we observed that these complexes are thermally unstable and that electron impact (EI), as well as field ionization (FI), mass spectrometry yielded spectra that show no ions representing the molecular masses. But FAB ionization readily provided $\mathrm{MH}^{+}$ions. The diethyldithiocarbamatonickel complexes, $\mathrm{Ni}(\mathrm{dtc})\left(\mathrm{PBu}_{3}\right)(\mathrm{SR})(\mathrm{dtc}=$ 
diethyldithiocarbamate, $\left.\mathrm{R}=\mathrm{C}_{6} \mathrm{H}_{5}, \mathrm{C}_{6} \mathrm{H}_{4} \mathrm{Cl}-4\right)$, in solution slowly form the dimeric compound $[\mathrm{Ni}(\mathrm{dtc})]_{2}-$ $(\mu-\mathrm{SR})_{2}$, a product that is similarly formed by the energetic EI conditions.

Mixed aryldichalcogenide bis(diphenylphosphino)ethanenickel(II) complexes are similarly found to have a gradation of stabilities in their mass spectra [3] depending on the nature of the aryldichalcogenide ligand. The stable complexes are the ones with homoleptic sulfur and as the ligands change to mixed chalcogenide ligands, so does the thermal stability of the complexes [3].

In the present study, we compare the behavior of the bis(diphenylphosphino)ferrocene (dppf) and bis(diisopropylphosphino)ferrocene (dippf) complexes mentioned above with those containing the bis(diphenylphosphino)ethane ligand, and observe what happens when the $\mathrm{Ni}$ is changed to other Group 10 metals.

Our aim was to compare the EI, FAB, and matrixassisted laser desorption ionization (MALDI) mass spectral behavior as well as their behavior with respect to the central metal atom. We found that the ferroceneanchored diphosphino ligands showed minor changes in the fragmentation profile of these complexes. Much of what we describe here is on the behavior of the complexes under EI and FAB ionization conditions. More elaborate studies have been carried out on their behavior under MALDI conditions. The results of these studies will be reported in a subsequent paper.

\section{Experimental}

\section{Materials and Methods}

All solvents were of analytical grade but were dried by procedures described previously [9]. 2-Mercaptophenol (Merck, Johannesburg, South Africa), and 3-nitrobenzyl alcohol (NBA, Aldrich, Dorset, England, UK), were used as received. Cesium iodide, $\alpha$-cyano-4-hydroxycinnamic acid, sodium iodide, and polyethylene glycol (PEG) for mass spectrometery were obtained from Aldrich and were also used as received. The starting materials, $\mathrm{Ni}(\mathrm{dppf}) \mathrm{Cl}_{2}$ and $\mathrm{Ni}(\operatorname{dippf}) \mathrm{Cl}_{2}$, were prepared by published procedures $[10,11]$. All the complexes that were used in this study were also synthesized by published procedures [12].

\section{Mass Spectrometry}

The EI and FAB mass spectrometry of all the compounds was performed on a JMS-HX100 EBE spectrometer (JEOL, Akishima, Japan). EI spectra were obtained at electron energy of $70 \mathrm{eV}$, an emission current of 100 $\mu \mathrm{A}$ and acceleration voltage of $5 \mathrm{kV}$. The ion source temperature was $250{ }^{\circ} \mathrm{C}$ and the temperature of the EI direct insertion probe (DIP) was programmed from $50{ }^{\circ} \mathrm{C}$ to $250{ }^{\circ} \mathrm{C}$ at $32{ }^{\circ} \mathrm{C} / \mathrm{min}$. FAB spectra of all the compounds were obtained with NBA as the matrix. Argon fast atoms were used to bombard the samples, dissolved in the matrix, on a stainless steel probe tip.
The ion source temperature was kept below $100{ }^{\circ} \mathrm{C}$ to prevent decomposition of the compounds. The mass spectrometer was calibrated using CsI.

MALDI mass spectrometry experiments were performed on a QTOF Ultima (Micromass Inc., Manchester, England). Nitrogen was introduced into the ion source to produce a pressure of 0.36 mbar. Desorption is by a nitrogen laser operating at $337 \mathrm{~nm}$ and $10 \mathrm{~Hz}$. The MALDI plate has an $8 \times 12$ array of sample wells plus one lock mass well for each cluster of four sample wells. For high resolution mass accurate spectra, the TOF analyzer was operated in the $\mathrm{W}$ mode with a resolving power of at least 14,000 . The matrix used was $\alpha$-cyano4-hydroxycinnamic acid as a $2 \mathrm{mg} / \mathrm{ml}$ solution in 50:50 acetonitrile:methanol. For calibration, a 2/1/1 mixture of PEG 200/600/1000 was used together with sodium iodide, and this solution was also used in the lock mass wells. A few sample crystals were added to $15 \mu$ l of the matrix solution, then $1 \mu \mathrm{l}$ of the mixture was deposited and evaporated in a sample well. Spectra were accumulated until a satisfactory signal/noise ratio had been obtained or for a period up to $2 \mathrm{~min}$.

\section{Results and Discussions}

Two main types of complexes, differing by the substituents on the phosphorus atoms, were studied. Type I had bis(diphenylphosphino)ferrocene (dppf) whilst Type II had bis(diisopropylphosphino) ferrocene (dippf) ligand. There were also variations of metals and thiolato ligands. For Type I, the metals were Ni (1), Pd (2), and

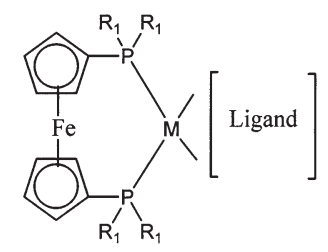

$\mathrm{M}=\mathrm{Ni}, \mathrm{Pd}$, or Pt; $\mathrm{R}_{1}=$ phenyl $($ Type I) or i-pr (Type II)

Ligands

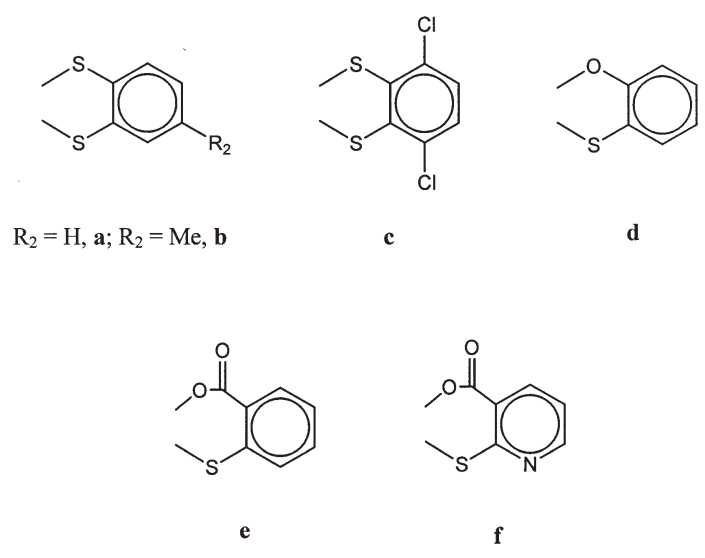

Scheme 1. Compounds studied. 
Table 1. Nominal and exact masses of the most intense peaks in the $\mathrm{M}^{+\cdot}$ or $\mathrm{MH}^{+}$clusters of aryldichalcogenide bis(diphenylphosphino)ferrocenenickel(II), 1

\begin{tabular}{ccccc}
\hline & & & \multicolumn{2}{c}{ MALDI } \\
\cline { 3 - 5 } Complex & EI & FAB & Measured & Calculated \\
\hline \hline 1a & N.O. & 753 & N.O. & $753.0202\left(\mathrm{MH}^{+}\right)$ \\
1b & 766 & 767 & $766.0269\left(\mathrm{M}^{+\cdot}\right)$ & 766.0280 \\
1c & & & $819.9360\left(\mathrm{M}^{+\cdot}\right)$ & 819.9345 \\
& N.O. & $821\left({ }^{58} \mathrm{Ni}\right)$ & $820.9418\left(\mathrm{MH}^{+}\right)$ & 820.9423 \\
\hline
\end{tabular}

Pt (3); for Type II, the metal was Pd (4). The general formula for the complexes and a description of the thiolato ligands are given in Scheme 1. Thus, four series of complexes were studied in total, the results of which are described below.

\section{Nickel Series}

Three complexes (1a-1c) of Aryldichalcogenide bis(diphenylphosphino)ferrocenenickel(II), 1, were studied. Using the three ionization techniques we found that only $\mathbf{1 b}$ gave a molecular radical cation $\left(\mathrm{M}^{+\cdot}\right)$ in EI mode while $\mathbf{1 a}, \mathbf{1} \mathbf{b}$, and $\mathbf{1 c}$ had ions in the molecular ion region of their FAB and MALDI spectra. Table 1 gives the masses of the most intense peaks in the molecular ion clusters of the complexes in the EI, FAB, and MALDI spectra. Unfortunately, the MALDI spectrum of Complex 1a did not have $\mathrm{M}^{+\cdot}$ or $\mathrm{MH}^{+}$ions at $m / z=752$ or 753 , respectively, although a $\mathrm{MH}^{+}$ion was observed in the FAB spectrum. Accurate masses were obtained with the MALDI-QTOF instrument which demonstrated that complex $\mathbf{1 b}$ surprisingly produced an $\mathrm{M}^{+}$. instead of an $\mathrm{MH}^{+}$, whereas complex 1c was observed to yield a $\mathrm{MH}^{+}$ion as well as a $\mathrm{M}^{+\cdot}$ ion (Figure 1).
The most prominent peak in the EI spectra of all the complexes was that at $m / z 586$. This fragment, $[\mathrm{dppfS}]^{+}$, was found at $m / z 587$ in the FAB spectrum of 1 a and $1 \mathrm{c}$ as the protonated species. We suggest that the positive charge on these complexes is centered on the dppf moiety which retains the charge on fragmentation. It is therefore apparent that both $\mathrm{m} / \mathrm{z} 586$ and 587 are the result of fragmentation of the $\mathrm{M}^{+\cdot}$ and $\mathrm{MH}^{+}$ions followed by rearrangement to produce the [dppfS $]^{+}$ and its protonated species, respectively. It is clear why in the three complexes, only $\mathbf{1 b}$ produced a $\mathrm{M}^{+\cdot}$ in the EI mode whereas in the case of the analogous dppe complexes, all of them gave $\mathrm{M}^{+\cdot}$ ions $[1,2]$ with a gradation of stabilities. The difference between the dppf and dppe Ni complex spectra could be explained in terms of the charge center. It seems that the chalcogen atoms stabilize the charge on $\mathrm{Ni}$, thus strengthening the $\mathrm{Ni}$ chalcogen bonds with a concomitant increase in the stability of the $\mathrm{M}^{+\cdot}$ ions. In the dppf analogs, however, the charge center seems to shift to the $\mathrm{Fe}$ in the ferrocene moiety and away from the chalcogens. The Ni chalcogen bonds are thus weakened and fragmentation takes place at these points rather more easily to produce the $[\mathrm{dppf}]^{+}$ion at $m / z=554$ which eliminates a phenyl and a diphenylphosphino $\left(\mathrm{PPh}_{2}\right)$ groups to give the ions [dppf-Ph] ${ }^{+}$at $m / z=477$ and $\left[\mathrm{dppf}-\mathrm{Ph}_{2} \mathrm{P}\right]^{+}$at $m / z=$ 369.

The FAB mass spectral fragmentations were similar for $1 a, 1 b$, and $1 c$ and are typified by the proposed fragmentation pattern in Scheme 2 . In the FAB spectra, there is a prominent peak at $m / z=612$. This could be produced as a result of fragmentation of the $\mathrm{MH}^{+}$ion to form [dppfNi] ${ }^{+}$. The absence of this ion in the EI spectra is most likely due to a weak phosphorus-Ni bond which fragments after the formation of the [dppfNi] ${ }^{+}$ion. A

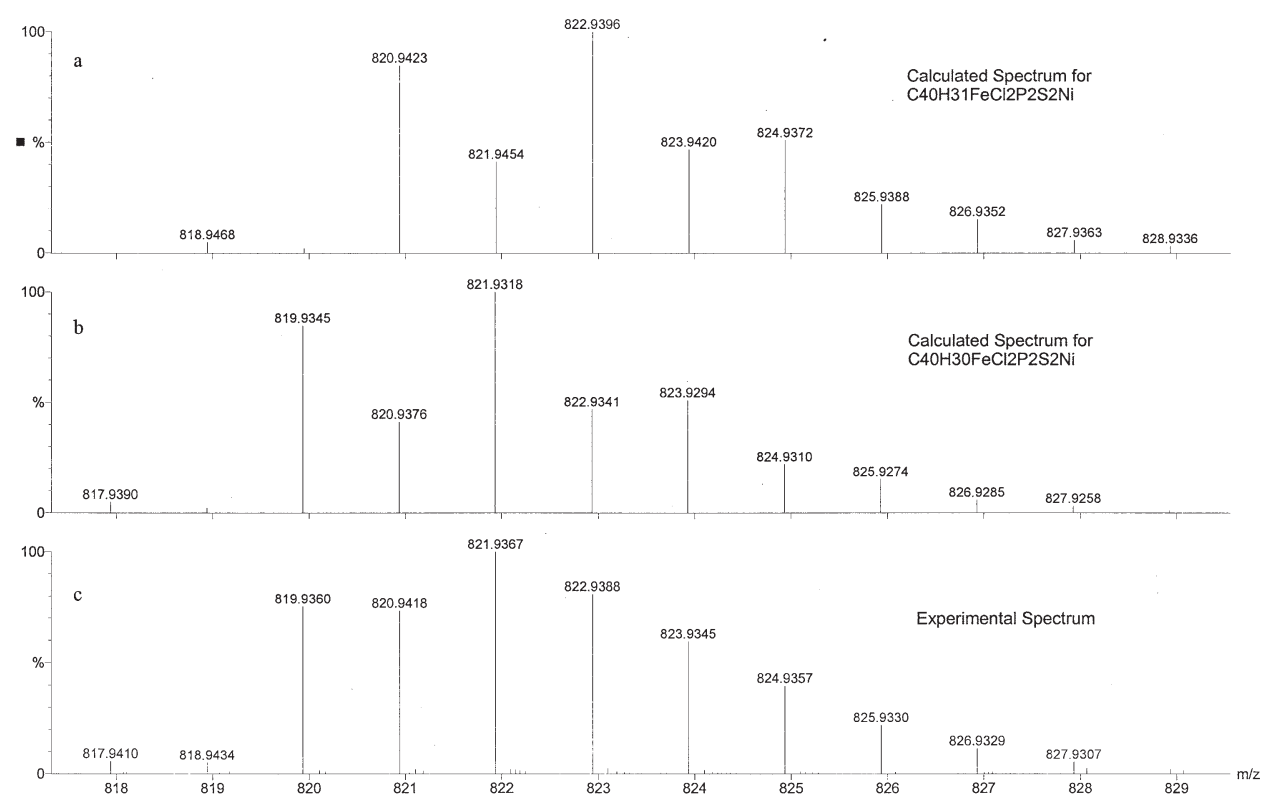

Figure 1. MALDI and simulated mass spectra of Compound 1c. 


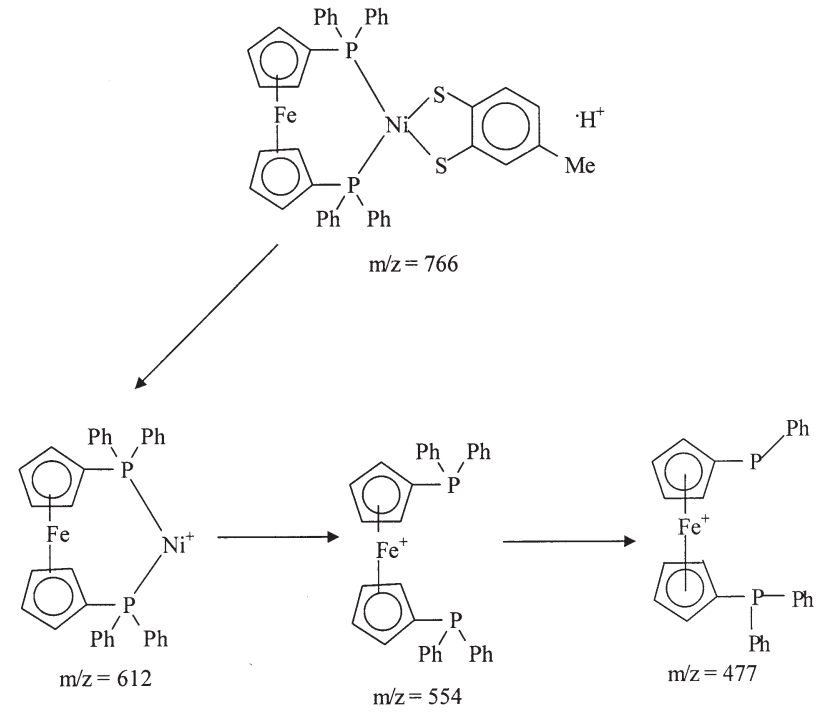

Scheme 2. Proposed fragmentation for FAB-generated $\mathrm{MH}^{+}$ ions of aryldichalcogenide bis(diphenylphosphino)ferrocenenickel(II) complex, $\mathbf{1 b}$.

similar explanation is offered for the irreversibility of redox behavior of $\mathrm{Ni}(\mathrm{dppf}) \mathrm{Cl}_{2}$ as oxidation leads to the decomposition of the oxidized species [13]. The fragment ions at $\mathrm{m} / \mathrm{z}=554$ and $\mathrm{m} / \mathrm{z}=477$ were also observed in the FAB spectra, though their intensities were low.

\section{Palladium Series Type I}

In the dppf Pd complexes, the spectra and fragmentation patterns were similar to those of the Ni complexes. The EI mass spectra were devoid of $\mathrm{M}^{+\cdot}$ ions. As in the case of series I complexes, Table 2 shows the nominal masses of the most intense ions in $\mathrm{MH}^{+}$clusters in the FAB spectra. The MALDI spectra of these complexes were not acquired. As was in the case of the $\mathrm{Ni}$ complexes, all the molecular ions eliminated the respective aryldichalogenide ligands to produce $[\mathrm{dppfPd}]^{+}$ $(\mathrm{m} / \mathrm{z}=660)$ and followed a fragmentation pattern similar to that in Scheme 2.

\section{Platinum Series}

For the dppf Pt complexes, there were ions representing the intact complexes in the EI (Figure 2), the FAB

Table 2. Nominal masses of the most intense ion in the $\mathrm{MH}^{+}$ clusters of the aryldichalcogenide bis(diphenylphosphino)ferrocenepalladium(II) complexes, 2

\begin{tabular}{cc}
\hline Complex & FAB \\
\hline \hline 2a & 801 \\
2b & 815 \\
2c & 871 \\
2d & 785 \\
2e & N.O. \\
2f & 814 \\
\hline
\end{tabular}

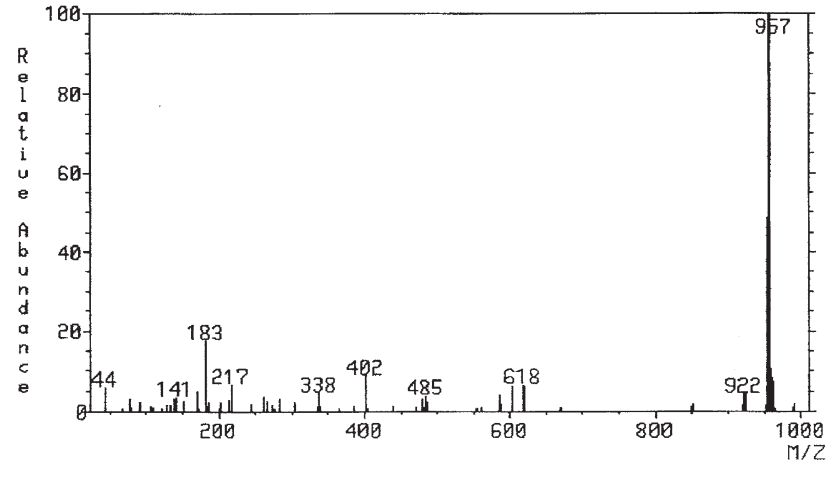

Figure 2. EI mass spectrum of 3c.

(Figure 3) and MALDI spectra (not shown) of all complexes (Table 3). Ions that were similar to those found in the spectra for the $\mathrm{Ni}$ and $\mathrm{Pd}$ complexes were $[(\mathrm{dppf}) \mathrm{Pt}]^{+}(m / z=749)$ and $[(\mathrm{dppf}) \mathrm{PtS}]^{+}(\mathrm{m} / \mathrm{z}=781)$. There were, however, some observed differences between theses Pt complexes and those of the first two. The first of these are formed by the loss of $\mathrm{CO}_{2}$ from $3 \mathbf{e}$ and $3 f$. They were the only two compounds that did not undergo serial fragmentation to yield $[\mathrm{dppf}]^{+}$. Most of the fragmentation pattern differences were found in the FAB spectra. For example, all the dithiolato ligand complexes $3 \mathbf{a}(\mathrm{m} / \mathrm{z}=890), \mathbf{3 b}(\mathrm{m} / \mathrm{z}=904)$ and $\mathbf{3 c}(\mathrm{m} / \mathrm{z}=$ 958) lost a phenyl group from the $\mathrm{MH}^{+}$ions.

Compared to the $\mathrm{Ni}$ and $\mathrm{Pd}$ complexes, the stability of the Pt complexes was generally higher. Removing an electron from any of these complexes, particularly if the positive charge resides on the Group 10 metal, results in the weakening of the metal-phosphorus bond. The extent of the metal-phosphorus bond weakening would thus determine the stability of the metal-containing fragment ion. From the reversible redox behavior observed for $\mathrm{Pt}(\mathrm{dppf}) \mathrm{Cl}_{2}$ [11], it is evident that the loss of an electron to form a $\left[\mathrm{Pt}(\mathrm{dppf}) \mathrm{Cl}_{2}\right]^{+}$ion does not affect the stability of the Pt-P bond and hence the rational for stable fragments for the $\mathrm{Pt}$ compounds in this study.

\section{Palladium Series Type II}

When the substituent on the phosphorus atom in the phosphine ligand was changed from phenyl to isopro-

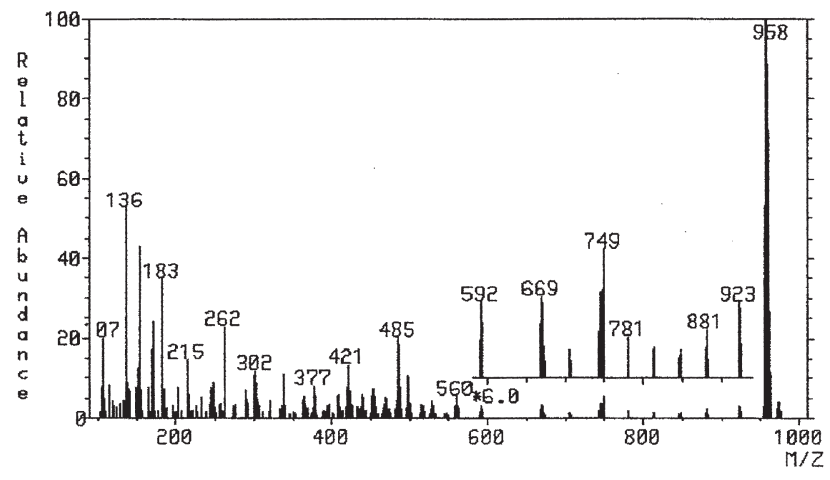

Figure 3. FAB mass spectrum of 3c. 
pyl, there was less fragmentation evident in the mass spectra. This was studied only for $\mathrm{Pd}$, but the trend could be expected to be similar for Pt due to the better stability of dppf $\mathrm{Pt}$ complexes described above. All three dithiolato complexes $(\mathbf{4 a}, \mathbf{4 b}, \mathbf{4 c})$ and the oxothiolato complex (4d) gave $\mathrm{M}^{+}$ions in the EI mode. Complexes $4 \mathbf{e}$ and $\mathbf{4 f}$ that contain $\mathrm{CO}_{2}$ as part of the thiolato ligands readily eliminated $\mathrm{CO}_{2}$ to give low intensity ions at $m / z=632$ and 633, respectively. In contrast to the EI spectra, all six complexes had either $\mathrm{M}^{+\cdot}$ or $\mathrm{MH}^{+}$ions in their FAB and MALDI spectra (Table 3), (Table 4). There is evidence from the FAB spectrum of $4 \mathrm{~b}$ to suggest that there are two fragmentation pathways for these compounds (Scheme 3). The first is the loss of the thiolato ligand to produce [dippfPd] $^{+}(m / z=524)$, which is the pathway of all the dppf complexes. This is followed by the loss of an isopropyl group to give the ion at $\mathrm{m} / \mathrm{z}=481$. The second pathway is unique to $\mathbf{4 b}$ and starts with a loss of an isopropyl group from the $\mathrm{MH}^{+}$ion $(\mathrm{m} / z=679)$ to produce a much weaker ion at $\mathrm{m} / \mathrm{z}=635$; this is followed by the loss of the dithiolato ligand to form the [dippfPd] ${ }^{+}$fragment. It is observed in the spectra of many of the compounds that the $\left[\right.$ dippfPd] ${ }^{+}$goes on to eliminate neutral propene to give an ion at $m / z=439$. In comparison to the dppf complexes, the dippf analog showed no tendency to lose the Group 10 metal. This is a sign that the more basic phosphine (dippf) stabilizes the interaction between the metal and the phosphine ligand in the $\mathrm{Pd}$ complexes. The ability of $\mathbf{4 b}$ to form a stable $\mathrm{MH}^{+}$ion at $m / z=679$ seems to be aided by the electron releasing methyl substituent on the dithiolato ligand in strengthening the Pd-S.

\section{Conclusions}

For Type I complexes, the $\mathrm{Pt}$ analogs were found to be the most stable of the three metals. Their EI spectra showed molecular ion clusters. Those containing the carboxyl group did not have any molecular ions because of the ease of $\mathrm{CO}_{2}$ elimination. The FAB and MALDI spectra were very similar. However, several of the compounds exhibited either $\mathrm{M}^{+\cdot}$ or $\mathrm{MH}^{+}$clusters,

Table 3. Nominal and exact masses of the most intense ion of $\mathrm{M}^{+\cdot}$ and $\mathrm{MH}^{+}$clusters of the aryldichalcogenide bis(diphenylphosphino)ferroceneplatinum(II) complexes, 3

\begin{tabular}{ccccc}
\hline & & & \multicolumn{2}{c}{ MALDI } \\
\cline { 4 - 5 } Complex & EI & FAB & \multicolumn{1}{c}{ Measured } & Calculated \\
\hline \hline 3a & 889 & 890 & $889.0469\left(\mathrm{M}^{+\cdot}\right)$ & 889.0418 \\
3b & 903 & 904 & $903.0640\left(\mathrm{M}^{+\cdot}\right)$ & 903.0574 \\
3c & 957 & 958 & $957.9609\left(\mathrm{MH}^{+}\right)$ & 957.9717 \\
3d & 873 & 874 & $873.0643\left(\mathrm{M}^{+\cdot}\right)$ & 873.0646 \\
3e & N.O* & 902 & $902.0748\left(\mathrm{MH}^{+}\right)$ & 902.0674 \\
3f & N.O* & 903 & $903.0635\left(\mathrm{MH}^{+}\right)$ & 903.0626 \\
\hline
\end{tabular}

*The molecular ion is not observed as it readily fragments to give the $\left[\mathrm{M}-\mathrm{CO}_{2}\right]^{+\cdot}$ radical cation.
Table 4. Nominal and exact masses of the most intense peak of $\mathrm{M}^{+\cdot}$ and $\mathrm{MH}^{+}$clusters of the aryldichalcogenide bis(diisopropylphosphino)ferrocenepalladium(II) complexes, 4

\begin{tabular}{ccccc}
\hline & & & \multicolumn{2}{c}{ MALDI } \\
\cline { 3 - 5 } Complex & EI & FAB & Measured & Calculated \\
\hline \hline 4a & 664 & 665 & $664.0508\left(\mathrm{M}^{+\cdot}\right)$ & 664.0438 \\
4b & 678 & 679 & $678.0621\left(\mathrm{M}^{+\cdot}\right)$ & 678.0587 \\
4c & 734 & 735 & $733.9697\left(\mathrm{M}^{+\cdot}\right)$ & 733.9641 \\
4d & 648 & 648 & $648.0746\left(\mathrm{M}^{+\cdot}\right)$ & 648.0667 \\
4e & N.O.* & 677 & $677.0691\left(\mathrm{MH}^{+}\right)$ & 677.0695 \\
4f & N.O.* & 678 & $678.0667\left(\mathrm{MH}^{+}\right)$ & 678.0646 \\
\hline
\end{tabular}

*The molecular ion is not observed as it readily fragments to give the $\left[\mathrm{M}-\mathrm{CO}_{2}\right]^{+\cdot}$ radical cation.

or both, in their MALDI spectra. Apart from $4 \mathbf{e}$ and $4 \mathbf{f}$, Pd Type II complexes gave $\mathrm{M}^{+\cdot}$ ions in EI indicating that these are more stable than the Type I analogs, and in FAB and MALDI all showed either $\mathrm{M}^{+\cdot}$ or $\mathrm{MH}^{+}$ion clusters. The MALDI spectrum of Compound 1c indicated the presence of both the $\mathrm{M}^{+\cdot}$ and the $\mathrm{MH}^{+}$ion clusters.

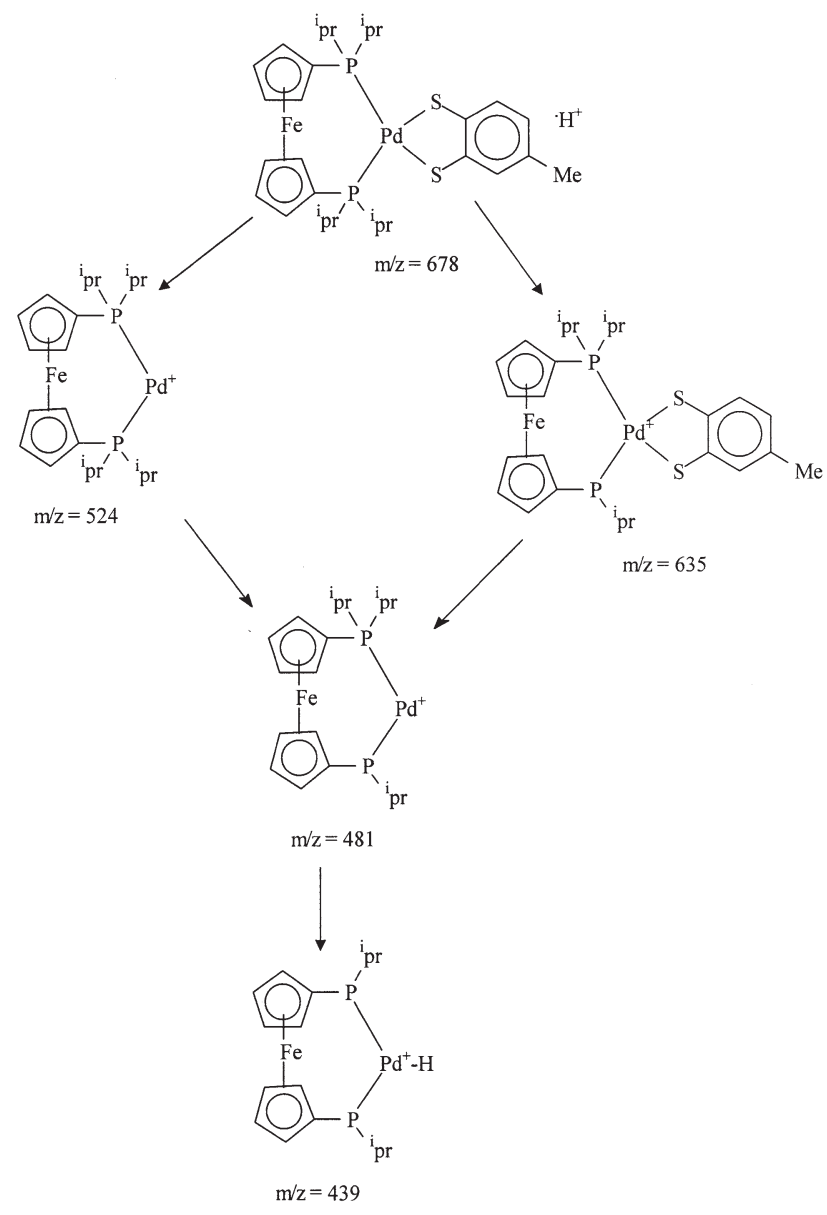

Scheme 3. Proposed fragmentation for FAB-generated $\mathrm{MH}^{+}$ ions of aryldichalcogenide bis(diphenylphosphino)ferrocenepalladium(II) complex, $\mathbf{4 b}$. 


\section{Acknowledgments}

Financial supports by the Research Institute, King Fahd University of Petroleum and Minerals, Saudi Arabia (EYOT and LL), the National Research Foundation, South Africa (JD and LLM) and the Canadian Institute for Health Research (AS and OM) are gratefully acknowledged.

\section{References}

1. Hayashi, T.; Konishi, M.; Kobori, Y.; Kumada, M.; Higuchi, T.; Hirotsu, K. Dichloro[1,1'-bis(diphenylphosphino)ferrocene]palladium(II): An effective catalyst for cross-coupling of secondary and primary alkyl Grignard and alkylzinc reagents with organic halides. J. Am. Chem. Soc. 1984, 106, 158-163.

2. Darkwa, J. Reversible absorption of sulfur dioxide by bis(diphosphino)ethanenickel(II) aryldithiolates, Inorg. Chim. Acta 1997, 257, 137-141.

3. (a) Thomas, M. S., Darkwa, J. Synthesis of bis(diphenylphosphino)ethanenickel(II) organodichalcogenide complexes and cyclotrimerization reaction of dimethylacetylene-dicarboxylate: Structure of Ni(dppe)(SC6H4O). Polyhedron 1998, 17, 1811-1815; (b) Thomas, M. S.; Darkwa, J.; Osei-Twum, E. Y.; Litorja, L. A., Jr. Synthesis, characterization, and stability of mixed aryldichalcogenide bis(diphenylphosphino)ethanenickel(II) complexes. X-ray structure of $\mathrm{Ni}(\mathrm{dppe})\left(\mathrm{SeC}_{6} \mathrm{H}_{4} \mathrm{~S}\right)$. Polyhedron 1999, 18, 2803-2810.

4. (a) McCaffrey, L. J., Henderson, W., Nicholson, B. K., Mackay, J. E., Dinger, M. B. Platinum(II), palladium(II), and nickel(II) thiosalicylate complexes. J. Chem. Soc. Dalton Trans. 1997, 15, 2577-2586; (b) Henderson, W.; Nicholson, B. K; McCaffrey, L. J. Applications of electrospray mass spectrometry in organometallic chemistry. Polyhedron 1998, 17, 4291-4313; (c) Henderson, W.; Evans, C. Electrospray mass spectrometric analysis of transitionmetal halide complexes. Inorg. Chim. Acta 1999, 294, 183-192; (d) Chin, C. C. H.; Yeo, J. S. L.; Loh, Z. H.; Vittal, J. J.; Henderson, W.; Hor, T. S. A. Synthesis and electrospray mass spectrometry of
palladium(II) diphosphine complexes from oxidative addition of 2-bromopyridine to $\operatorname{Pd}(0)$. J. Chem. Soc. Dalton Trans. 1998, 22, 3777-3784.

5. Traeger, J. C. Electrospray mass spectrometry of organometallic compounds. Int. J. Mass Spectrom. 2000, 200, 387-401.

6. Asker, K. A.; Greenway, A. M.; Seddon, K. R.; Shimran, A. A. Characterization of bis(Diphenylphosphino)methane and bis(diphenylphosphinomethyl)phenylphosphine complexes of platinum(II) and palladium(II) by fast-atom-bombardment mass spectrometry. J. Organomet. Chem. 1988, 354, 257-271.

7. Oberhauser, W. Bachmann, C. Stampfl, T. Haid, R. Langes, C. Rieder, A. Bruggeller, P.Nickel(II), palladium(II), platinum(II), and platinum(IV) complexes of cis-1,2-bis(diphenyl-phosphino)ethene and nitrogen-containing heterocycles or sulfur ligands. Inorg. Chim. Acta 1998, 274, 143-154.

8. Darkwa, J.; Osei-Twum, E. Y.; Litorja, L. A. Jr. Synthesis and characterization of mono- and dinuclear diethyldithiocarbamatonickel(II) organochalcogenide complexes. Polyhedron 1999, 18, 1115-1122.

9. Darkwa, J.; Bothata, F.; Koczon, L. M. Synthesis and characterization of cyclopentadienyl-nickel(II) thiolates. Crystal structure of $\left[\left(\eta 5-\mathrm{C}_{5} \mathrm{H}_{5}\right) \mathrm{Ni}\left(\mathrm{SC}_{6} \mathrm{H}_{5}\right)\left(\mathrm{PPh}_{3}\right)\right]$. J. Organomet. Chem. 1993, 455, 235-240.

10. Van Hecke, G. R.; de Horrocks, W., Jr. Ditertiary phosphine complexes of nickel. Spectral, magnetic, and proton resonance studies. A planar-tetrahedral equilibrium. Inorg. Chem. 1966, 5, 1968-1974.

11. Woollins, J. D. Inorganic Experiments; VCH: Weinheim, 1994; p 61.

12. Maisela, L. L.; Crouch, A. M.; Darkwa, J.; Guzei, I. A. Bidentate aryldichalcogenide complexes of [(diphosphino)ferrocene]palladium(II) and [(diphosphino)ferrocene]- platinum(II). Synthesis, molecular structures, and electrochemistry. Polyhedron 2001, 20, 3189-3200.

13. Gan, K.-S.; Hor, T. S. A. In Ferrocenes; Togni, A.; Hayashi T., Eds.; VCH: Weinheim, 1995; p 93. 